\title{
UNA REVISIÓN DE LA POTESTAD DE AUTORREGLAMENTACIÓN DEL DEFENSOR DEL PUEBLO DESDE LA PERSPECTIVA DE LA TEORÍA DE LAS FUENTES DEL DERECHO
}

\author{
IGNACIO GONZÁLEZ GARCÍA \\ Profesor Ayudante Doctor Derecho Constitucional \\ Universidad de Murcia
}

\author{
SUMARIO \\ I. Planteamiento de la cuestión. \\ II. La autonomía orgánica y funcional del \\ Defensor del Pueblo constitucionalmen- \\ te garantizada. \\ III. La exclusión del régimen interno del De- \\ fensor del Pueblo de la reserva a Parla- \\ mento. \\ IV. Las relaciones del Reglamento interno \\ con la Ley Orgánica del Defensor del \\ Pueblo: conflicto fronterizo.
}

\section{PLANTEAMIENTO DE LA CUESTIÓN}

\section{I.1. El Desarrollo normativo}

Como bien es conocido, el artículo 54 de nuestra Constitución remite al legislador orgánico la regulación del Defensor del Pueblo, órgano que será designado por el Parlamento para la defensa de los derechos comprendidos en el Título I de la Norma Fundamental, a cuyo efecto podrá "supervisar la actividad de la Administración, dando cuenta a las Cortes Generales". Quedan, pues, así configurados en el Texto Constitucional los elementos esenciales de la institución: el para qué de su existencia en nuestro sistema; el cómo va a poder desarrollar la función que la Constitución le encomienda, lo que presume la atribución de determinadas potestades para llevarla a cabo; y los términos de su particular relación con el Parlamento, órgano constitucional que 
realiza la designación de su titular, que debe estar además informado del desarrollo de sus actividades y del que el Defensor del Pueblo es, en fin, — dice el citado precepto- "alto comisionado".

En el desarrollo de este mandato constitucional, el legislador orgánico ha recogido de forma inequívoca —art. 6.1 y concordantes de la Ley Orgánica del Defensor del Pueblo (en adelante, LODP)— la autonomía de que el Defensor del Pueblo goza para el ejercicio de sus funciones:

«El Defensor del Pueblo no estará sujeto a mandato imperativo alguno. No recibirá instrucciones de ninguna autoridad. Desempeñará sus funciones con autonomía y según su criterio".

Como veremos con mayor detalle en las páginas siguientes, muchos otros artículos de la LODP concretan el ámbito de esta autonomía orgánica y funcional, pero ninguno de ellos recoge de forma expresa la capacidad de autonormación del Defensor del Pueblo, excepción hecha de una referencia a la presunta existencia de un "Reglamento" ${ }^{1}$ que, con carácter absolutamente incidental, contiene el artículo 34 LODP, el cual permite al titular de la institución designar libremente a los asesores necesarios para el ejercicio de sus funciones "de acuerdo con el Reglamento y dentro de los límites presupuestarios".

A ello se añade, además, que ni la LODP, por supuesto, ni ninguna otra norma de nuestro ordenamiento jurídico —en particular, los Reglamentos del Congreso de los Diputados y del Senado- hacen referencia al órgano competente para la aprobación de este tipo normativo ni a su procedimiento de elaboración.

Pese a tal circunstancia, las Mesas de ambas Cámaras aprobaron, en sesión conjunta de 6 de abril de 1983, y a propuesta del propio Defensor del Pueblo ${ }^{2}$, el correspondiente Reglamento de Organización y Funcionamiento interno de este órgano; probablemente acogiéndose a la competencia residual de la Mesa de la Cámara prevista en el artículo $31.1 .7^{\circ}$ del RCD —no así en el precepto paralelo del RS - que permite a la misma llevar a cabo aquellas funciones parlamentarias "que no estén atribuidas a un órgano específico". Todo ello, claro está, en el entendido - mal entendido, según defenderemos en las próximas páginas- de que corresponde a las Cortes Generales la decisión última sobre cómo debe el Defensor del Pueblo ordenar su propio funcionamiento interno.

Con carácter general, aquellas Comunidades Autónomas que cuentan con una institución semejante han reproducido un esquema muy similar al estatal.

1 Sobre los graves inconvenientes de encontrar en nuestro ordenamiento jurídico la reiterada utilización del término reglamento para hacer referencia a "una pluralidad de normas, de muy diverso origen, que manifiestan una voluntad normativa fuertemente diferenciada y cuyo régimen jurídico difiere igualmente en profundidad", vid. BALAGUER CALLEJÓn, F., Fuentes del Derecho, Vol. II, Tecnos, Madrid, 1991, pág. 97.

2 Como se desprende fácilmente de una sucinta comparación entre el texto propuesto por el Defensor del Pueblo y el finalmente aprobado por las Mesas de las Cámaras, éstas no se limitaron a ratificar la propuesta remitida por aquél sino que introdujeron notables modificaciones a su contenido. Vid. Diario de Sesiones del Congreso de los Diputados, Comisión Mixta, n. ${ }^{\circ} 1$, de 21 de abril de 1983. 
Así, lo habitual es que el correspondiente Estatuto de Autonomía recoja un precepto paralelo al del artículo $54 \mathrm{CE}$ donde, tras describir sus elementos esenciales, se remite al legislador autonómico la normación de estos comisionados territoriales ${ }^{3}$; y que la consiguiente ley autonómica, amén de otras similitudes con la ley orgánica estatal, contenga un artículo casi literalmente idéntico al 6.1 LODP antes aludido. Sirva como ejemplo de lo dicho el caso andaluz:

Art. 128.2 EAAnd: «El Defensor del Pueblo andaluz será elegido por el Parlamento por mayoría cualificada. Su organización, funciones y duración del mandato se regularán mediante ley".

Art. 6 Ley 9/1983, de 1 de diciembre, reguladora del Defensor del Pueblo Andaluz: «El Defensor del Pueblo Andaluz no estará sujeto a mandato imperativo alguno. No recibirá instrucciones de ninguna autoridad. Desempeñará sus funciones con autonomía y según su criterio”.

A mayor abundamiento, sucede que la generalidad de estas normas autonómicas no sólo no establece - también a imitación del modelo estataluna cláusula expresa referida a la capacidad de autonormación de este órgano sino que, además, ha recogido la práctica estatal extra legem y ha previsto en sus textos la aprobación, a propuesta de los comisionados autonómicos, de sus Reglamentos de Organización y Funcionamiento por parte de los Parlamentos regionales, bien a través exclusivamente de la Mesa de las Cámaras ${ }^{4}$, bien por la Mesa previo acuerdo de la Junta de Portavoces o de la Comisión parlamentaria que corresponda ${ }^{5}$, bien incluso a través del propio Pleno de tales Cámaras territoriales ${ }^{6}$.

3 Algunas Comunidades Autónomas, v.g. la Comunidad Autónoma de la Región de Murcia, no se refieren expresamente en su Estatuto a la creación del Defensor del Pueblo autonómico. No obstante, tanto la propia LODP como la jurisprudencia constitucional habida hasta la fecha aportan la cobertura jurídica suficiente para la creación de estos órganos institucionales también en tales Comunidades Autónomas. Vid., por todos, GARRORENA MORALES, A.: "La actividad de la Comunidad Autónoma de la Región de Murcia", en TORNOS MAS, J. (Dtor.), Informe Comunidades Autónomas 2008, IDP, Barcelona, 2009, págs. 558-559.

4 V.g. art. 48 de la Ley 6/2008, de 20 de noviembre, del Defensor del Pueblo de la Región de Murcia: «El Defensor del Pueblo de la Región de Murcia elaborará su reglamento de organización y funcionamiento y lo elevará a la Mesa de la Asamblea Regional para su tramitación y aprobación, dando cuenta al Pleno" (redacción dada por Ley 9/2009, de 23 de noviembre). Texto original del precepto: «El Defensor del Pueblo de la Región de Murcia elaborará su reglamento de organización y funcionamiento y lo elevará a la Mesa de la Asamblea Regional para su tramitación y aprobación por el Pleno de la Cámara".

5 V.g. disp. ad. única Ley 4/1985, de 27 de junio, reguladora del Justicia de Aragón: «Para el desarrollo de la presente Ley el Justicia podrá presentar ante la Mesa de las Cortes un proyecto de Reglamento de Organización y Funcionamiento de la Institución, que será debatido y aprobado por dicha Mesa, con el acuerdo de la Junta de Portavoces". Disp. ad. $1^{a}$ Ley 6/2006, de 2 de mayo, del Defensor del Pueblo Riojano: "Se autoriza al Defensor del Pueblo Riojano para dictar las normas reglamentarias precisas para el desarrollo de la presente Ley, de acuerdo con la Mesa del Parlamento de La Rioja y la Comisión Parlamentaria correspondiente».

6 V.g. art. 37.2 Ley 5/2005, de 16 de diciembre, del Procurador General del Principado de Asturias: «El proyecto de Reglamento de Organización y Funcionamiento será elaborado por el Pro- 
Especialmente indicativo de la idea que tienen los Parlamentos autonómicos de estos Reglamentos de Organización y Funcionamiento interno de los Defensores del Pueblo como una norma propia sobre la que son ellos quienes tienen la capacidad de decidir, casi como un anexo parlamentario a la norma con rango de ley que regula la institución se tratara, es el hecho de que encontremos en muchos de estos Reglamentos cláusulas a través de las cuáles el Parlamento autoriza, habilita o faculta al Defensor del Pueblo para dictar las instrucciones o resoluciones precisas para integrar o desarrollar el contenido de la citada norma; esto es, la institución parlamentaria insiste en dejar claro que le corresponde a ella regular el régimen de organización y funcionamiento interno del Defensor del Pueblo, resultando incluso la capacidad de éste para integrar las normas reglamentarias aprobadas en sede parlamentaria no la manifestación de un poder autónomo del comisionado autonómico sino, muy al contrario, la consecuencia de una expresa delegación por parte de tales Parlamentos. Baste señalar aquí el ejemplo castellanoleonés:

Disp. ad. $2^{\text {a }}$ ROF Procurador del Común (aprobado por la Mesa de las Cortes de Castilla-León el 31 de marzo de 2003): "Se autoriza al Procurador del Común a adoptar los acuerdos y dictar las instrucciones necesarias para el desarrollo de lo previsto en el presente Reglamento" ${ }^{7}$.

Las dos excepciones a este común denominador normativo autonómico (y excepciones muy atendibles, porque balancean el tema hacia el lado del reconocimiento de una auténtica potestad de autoformación del Defensor del Pueblo) son las regulaciones del Ararteko de la Comunidad Autónoma del País Vasco y del Sindic de Greuges de la Comunidad Autónoma catalana. Ambas se sitúan en el extremo opuesto de lo hasta ahora descrito, ya que aceptan expresamente la capacidad de autorreglamentación de su comisionado autonómico, excluyendo, por tanto, cualquier otro tipo de intervención parlamentaria en la elaboración, aprobación y reforma de su Reglamento interno. La diferencia, nada desdeñable, entre ambos casos es que en el País Vasco es la Ley 3/1985, de 27 de febrero, por la que se crea y regula la Institución del Ararteko, la norma que realiza ese expreso reconocimiento —-el Reglamento interno del Ararteko será aprobado

curador General, que lo elevará a la Junta del Principado de Asturias, por conducto de su Mesa, para su tramitación y, en su caso, aprobación por el Pleno, en los términos que se establezca en el Reglamento de la Cámara".

7 En este mismo sentido, vid. la disp. ad. $5^{\text {a }}$ ROF del Defensor del Pueblo andaluz (aprobado por la Mesa del Parlamento andaluz, el 20 de noviembre de 1985), la disp. ad. $1^{\text {a }}$ ROF del Defensor del Pueblo de la Región de Murcia (aprobado por la Mesa de la Asamblea Regional, el 4 de diciembre de 2009), la disp. ad. $3^{a}$ ROF del Defensor del Pueblo riojano (aprobado por la Mesa del Parlamento de La Rioja, el 14 de septiembre de 2007) y la disp. ad. $2^{\mathrm{a}}$ ROF del Procurador General del Principado de Asturias (aprobado por la Junta General del Principado de Asturias, el 5 de enero de 2007). 
por él mismo [...]", reza la disp. ad. $2^{\text {a }}$ de ese cuerpo legal一; mientras que en Cataluña es nada menos que el propio Estatuto de Autonomía quien así lo establece — «...] el Sindic de Greuges goza de autonomía reglamentaria, organizativa y funcional", afirma su art. 79.3- Como veremos en el epígrafe correspondiente, que entendamos que es una u otra fuente la que atribuye al Defensor del Pueblo la potestad de autonormarse puede afectar de modo notable al esquema de relaciones que se vayan a establecer entre la ley reguladora de esta institución y el reglamento de organización y funcionamiento interno de la misma.

\section{I.2. UN DEBATE DOCTRINAL INACABADO}

Ante este panorama normativo, los pronunciamientos doctrinales que encontramos en nuestra literatura jurídica podríamos ordenarlos en dos grandes bloques.

Un sector minoritario se ha decantado por entender que la organización y el funcionamiento interno de una institución como el Defensor del Pueblo es materia a regular por las Cortes Generales en tanto aquél se encuentra estrechamente vinculado a éstas desde el punto de vista orgánico, como alto comisionado de las mismas. Desde esa óptica, se defiende que habrían de ser no ya las Mesas de ambas Cámaras sino sus Plenos quienes aprobaran el Reglamento, cuyo proyecto además no habría de llegar al Parlamento a propuesta del Defensor del Pueblo porque serían también las Cortes quienes debieran monopolizar tal iniciativa. Se debería integrar, por tanto, esta materia en el ámbito de la reserva al Reglamento de las Cámaras que hace la Constitución en su artículo 72 y concordantes, por lo que habría de formar parte, en su caso, del hasta ahora inédito Reglamento de las Cortes Generales. Todo ello, bajo nuestro punto de vista, sin justificar suficientemente ninguna de tales afirmaciones. Traemos aquí, por elocuentes, las palabras de Oehling Ruiz:

"Cabría entender que quien puede lo más, puede lo menos, y si las Cortes Generales aprobaron la ley orgánica, podrán aprobar este Reglamento. [...] lo que también extraña es que haya sido a propuesta del propio Defensor del Pueblo [...]. Entendemos en todo caso que, vinculado orgánicamente a las Cortes, no cabe duda de su capacidad para reglamentarlo, [...] pero que debieran haber sido los Plenos con la reforma de sus actuales Reglamentos como mínimo, como con más coherencia han hecho los Parlamentos andaluz y catalán [sic] para reglamentar a sus Comisionados o como parte del desarrollo del Reglamento de las Cortes Generales previsto en el artículo 72 de la Constitución".

8 OEHLING RUIZ, H.: "El Defensor del Pueblo: algunos problemas en su adaptación orgánico-funcional", en $R E P$, n. ${ }^{\circ} 72,1991$, págs. 97 y 98. 
En un sentido similar, si bien que de forma mucho más moderada y casi como mera sugerencia, se ha expresado Pérez $\mathrm{Calvo}^{9}$, quien afirma que:

«[...] aunque podría pensarse que el mencionado Reglamento [de organización y funcionamiento del Defensor del Pueblo] debía haber sido previsto para las Cortes Generales en su conjunto en el art. 72.2 de la Constitución o, más previsiblemente, uno específico para el Defensor, aprobado por los Plenos de ambas Cámaras, finalmente se ha optado por el ya citado Reglamento de Organización y funcionamiento del Defensor del Pueblo aprobado el 6 de abril de 1983 por las Mesas del Congreso y del Senado en sesión conjunta".

Sin embargo, un sector doctrinal mayoritario se ha inclinado por criticar la participación de las Cortes Generales, a través de las Mesas del Congreso y del Senado, en la elaboración y aprobación de este Reglamento de régimen interno del Defensor del Pueblo, usando para ello el argumento - casi exclusivo- de que el artículo 6.1 LODP y demás concordantes de la misma norma atribuyen al Defensor del Pueblo un ámbito de autonomía funcional y orgánica que justificaría la aprobación unilateral por éste de su propio reglamento. Dicho de otro modo, en opinión de estos autores, la LODP configura una institución dotada de un nivel de autonomía respecto de las Cortes Generales que incluye, implícitamente, la capacidad de este órgano para autorreglamentarse. Así, afirma González-Ares ${ }^{10}$ :

«El requisito de la ulterior aprobación por el Parlamento de un texto que únicamente produce efectos en el ámbito interno de la institución del Defensor del Pueblo parece contradecir lo preceptuado en el artículo 6 de su Ley Orgánica [...], ya que de esta forma las Cortes dan instrucciones concretas al Defensor del Pueblo acerca del modo en que esta institución ha de organizarse. [...] El Reglamento de Organización y Funcionamiento del Defensor del Pueblo debería, por tanto, haber sido aprobado por decisión única de la institución y ser modificada por esta misma única decisión ${ }^{11}$.

Cabe destacar de ello, porque resultará una pieza importante cuando planteemos más adelante nuestra postura al respecto, que estos autores se refieren a la LODP como si ésta, en el desarrollo del artículo $54 \mathrm{CE}$, hubiera podido optar libremente por dotar o no de autonomía a la institución, o hacerlo

9 PÉREZ CALVO, A.: "Comentario al artículo 54", en ALZAGA VILlAAMIL, O. (Dtor.), Comentarios a la Constitución Española de 1978, Edersa, Madrid, 1999, pág. 544.

10 GONZÁLEZ-ARES, J.A., El Valedor do Pobo. Del Ombudsman sueco al comisionado parlamentario gallego, Tirant lo Blanch, Valencia, 2005, pág. 157.

$11 \mathrm{Vid}$., también, en términos idénticos, PÉREZ-UGENA COROMINA, M., Defensor del Pueblo y Cortes Generales, Congreso de los Diputados, Madrid, 1996, pág. 249-253. 
en unos términos más o menos amplios ${ }^{12}$. Entienden, pues, la potestad de autonormación del Defensor del Pueblo como una decisión - constitucionalmente válida, claro está - del legislador orgánico y, como tal, quedaría en sus manos la concreta delimitación del correspondiente ámbito de aquélla.

\section{I.3. Un PUNTO DE PARTIDA DIFERENTE}

A nuestro juicio, el modo de abordar esta cuestión habría de ser muy distinto. De una parte, cuál sea el órgano que aprueba una determinada norma constituye, sin lugar a dudas, un indicio muy relevante - aunque, ni mucho menos exclusivo- de cuáles pueden ser la naturaleza jurídica y el rango normativo de ésta, pero tal circunstancia no nos debe hacer concluir, en el caso que nos ocupa, que la vía de hecho adoptada por las Cortes Generales al modificar y aprobar el Reglamento de Organización y Funcionamiento propuesto por el Defensor del Pueblo convierte el ámbito propio de esta norma en materia parlamentaria, a incorporar o asimilar, por tanto, a los respectivos Reglamentos de las Cámaras. Aunque resulte evidente, debemos insistir en que, en nuestro sistema, las potestades normativas no pueden presumirse: desde la Constitución hasta la última resolución integradora de los Reglamentos de Congreso y Senado no encontramos norma alguna que exija o siquiera justifique mínimamente la participación de las Cortes Generales en la aprobación del Reglamento de régimen interno del Defensor del Pueblo.

Desde una perspectiva complementaria, pero distinta, creemos que es además necesario advertir que la LODP reconoce en diversos preceptos un alto nivel de autonomía orgánica y funcional a esta institución, lo que, dando un paso más, nos debería llevar a preguntarnos por qué lo hace, si es absolutamente libre en la toma de tal decisión y, sobre todo, si, vistas las razones por las que lo hace, la mencionada autonomía debe extenderse o no a su normación interna. Habría que comenzar, pues, por concretar cuál es la efectiva relación que la Constitución establece entre el Defensor del Pueblo y las Cortes Generales, a fin de ver hasta qué punto existe dependencia de aquél respecto de éstas; habría que continuar considerando -ésta es la clavecómo ha configurado desde el punto de vista funcional al Defensor del Pueblo nuestro Texto Constitucional; y si, a consecuencia de ello, goza o no esta institución de un ámbito de autonomía constitucionalmente garantizada que el legislador orgánico deba, en todo caso, respetar y que bien pudiera justificar la reclamación de las potestades de autonormación ad intra que aquí nos

12 Vid., por todos, PÉREZ CALVO, A.: «[...] la alternativa frente a la que se colocaba la LODP era el mayor o menor grado de dependencia del Defensor del Pueblo respecto de las Cortes. Pues bien: la LODP ha optado por dotar al Defensor del Pueblo de una amplia autonomía funcional [...]", en "Rasgos esenciales del Defensor del Pueblo según la Constitución y la Ley Orgánica 3/1981, de 6 de abril», en $R D P$, n. $^{\circ} 11,1981$, págs. 67-68. 
ocupan ${ }^{13}$. Sólo tras resolver estos interrogantes estaremos en disposición de fundamentar convenientemente la titularidad de tales potestades y, con ello, la pertinencia o no de la participación de las Cortes Generales en la aprobación del referido Reglamento de Organización y Funcionamiento del Defensor del Pueblo. A partir de ahí, será más fácil —más riguroso también- determinar su verdadera naturaleza y, por tanto, las líneas rojas que delimitan el ámbito que le es propio frente al de otros tipos normativos, en particular, frente a los Reglamentos de las Cámaras y a la LODP.

\section{LA AUTONOMÍA ORGÁNICA Y FUNCIONAL DEL DEFENSOR DEL PUEBLO CONSTITUCIONALMENTE GARANTIZADA}

El artículo $54 \mathrm{CE}$, al describir las notas esenciales del régimen jurídico del Defensor del Pueblo, se refiere a algunos elementos que indicarían, en una primera aproximación, una clara relación de dependencia de esta figura respecto de las Cortes Generales, pero también a otros que parecen garantizar su plena autonomía orgánica y funcional frente al Parlamento.

Así, de un lado, la Constitución configura al Defensor del Pueblo como un "alto comisionado" de las Cortes Generales, a quienes corresponde su designación y frente a quienes ha de rendir cuentas de su actividad. En desarrollo de tales previsiones, la LODP ha establecido: las condiciones del nombramiento parlamentario del Defensor del Pueblo (art. 2) y las causas de cese, que incluyen -entre otras-, el actuar con notoria negligencia en el cumplimiento de las obligaciones y deberes del cargo", circunstancia cuya concurrencia decidirá una mayoría cualificada de cada una de las Cámaras (art. 5.1.4); los concretos términos en los que el Defensor del Pueblo habrá de articular la rendición de cuentas al Parlamento, principalmente vía informe anual (arts. 32 y 33); así como, finalmente, la dependencia presupuestaria de este órgano respecto de las Cortes Generales, ya que su dotación económica constituye una partida inserta en el presupuesto de las mismas (art. 37).

Sin embargo, de otra parte, la Constitución también realiza de modo inequívoco, en ese mismo precepto, la atribución al Defensor del Pueblo de una función propia, específica e independiente de las que ostenta la institución parlamentaria: la defensa de los derechos comprendidos en el Título I de

13 El único autor que ha avanzado por esta senda argumental ha sido VARELA SUANZESCARPEGNA, aunque sin llegar a extraer de ella, como veremos más adelante, las importantes consecuencias que se derivan respecto de la naturaleza jurídica del ROFDP: "La defensa y la garantía de los derechos fundamentales constituye, efectivamente, la finalidad e incluso la causa, la razón de ser, del Defensor del Pueblo. Su por qué y su para qué. El control de la actividad administrativa y el impulso de la jurisdicción constitucional son sólo los medios que el ordenamiento pone a su alcance para realizar tan alta y delicada labor. Por tal motivo es lógico que, [...] aquel telos delimite el alcance de estos dos medios, de estas dos funciones de control, y a la vez explique la peculiar autonomía orgánica y funcional que el Defensor del Pueblo goza respecto de las Cortes", en "La naturaleza jurídica del Defensor del Pueblo", en REDC, n. ${ }^{\circ}$ 8, 1983, pág. 79. 
la Norma Fundamental. Y no sólo eso, sino que, además, pone al servicio de tal fin dos importantes medios de los que podrá disponer el Defensor del Pueblo: el control de la actividad de la Administración (art. 54); y el impulso de la jurisdicción constitucional a través de su legitimación para interponer recursos de inconstitucionalidad y de amparo (art. 162.1.a y b), lógicamente también frente a normas o actos emanados del propio Parlamento. El normal desarrollo de esta función y la eficaz utilización de estos medios por parte del Defensor del Pueblo hacen absolutamente imprescindible habilitar las condiciones de autonomía orgánica y funcional que garanticen el buen fin de los mismos, y así lo ha hecho el legislador orgánico en desarrollo de las previsiones constitucionales, no sólo en el importantísimo y ya citado artículo 6.1 LODP —El Defensor del Pueblo no estará sujeto a mandato imperativo alguno. No recibirá instrucciones de ninguna Autoridad. Desempeñará sus funciones con autonomía y según su criterio»-, sino también en muchos otros preceptos de esa norma que responden al mismo espíritu: un rigurosísimo régimen de incompatibilidades, especialmente respecto de profesiones o tareas relacionadas con la actividad política (art. 7.1); un mandato de duración superior a una Legislatura (art. 2.1); unas mayorías muy cualificadas para la designación y el cese (arts. 2.4 y 5.2); una desvinculación total de las vicisitudes propias de la vida de las Cámaras, no resultando afectada la actividad del Defensor del Pueblo por los supuestos de disolución, expiración del mandato o vacaciones parlamentarias (art. 11.1); un estatuto jurídico particular que lo dota de inviolabilidad e inmunidad, sin dependencia de suplicatorio a las Cortes Generales en este último caso (art. 6.2 y 3); unos procedimientos de investigación para el esclarecimiento de los actos y resoluciones de la Administración Pública y de sus agentes que puede iniciar de oficio; etcétera.

Si además tenemos en cuenta que, salvo la dependencia económica del presupuesto de las Cortes Generales —elemento introducido por la LODP que entendemos poco compatible con la letra y el espíritu de la regulación constitucional-, las otras dos notas de aparente dependencia respecto de la institución parlamentaria (rendición de cuentas y designación por el Parlamento) no constituyen menoscabo alguno de la autonomía orgánica y funcional del Defensor del Pueblo ${ }^{14}$, cabría concluir que éste no es un verdadero fiduciariocomisionado de la institución parlamentaria puesto que, sencillamente, carece

14 Respecto del informe anual del Defensor del Pueblo a las Cortes Generales, PÉREZ CALVO afirma que éste no tiene exclusivamente un "carácter de rendición de cuentas, sino que, [...] algunos de ellos [informes] pueden constituir una denuncia ante las Cortes como último recurso que puede quedar al Defensor del Pueblo para llevar a cabo su misión", en "Rasgos esenciales del Defensor del Pueblo..., op. cit., págs. 68 y 69. Por lo que hace a la designación parlamentaria del Defensor del Pueblo entendemos trasladables aquí las reflexiones de PUNSET BLANCO acerca de la compatibilidad entre la autonomía e independencia de un órgano con la designación de su titular por parte de otro: "Se trata, por tanto, de cualidades [autonomía e independencia] compatibles con la existencia de un órgano supremo [...], con la designación o elección de los miembros de un órgano por parte de los componentes de otro u otros [...], en "Potestades normativas y forma de Gobierno", en REDC, n. ${ }^{\circ}$ 87, 2009, pág. 12. 
de las características esenciales propias de tales figuras. En palabras de Sainz Moreno ${ }^{15}$ :

"La autonomía que se reconoce al Defensor del Pueblo incluso frente a las Cortes, y su desvinculación de las vicisitudes que éstas experimentan (coaliciones de grupos parlamentarios, disoluciones de las Cámaras, etc.) no guarda relación con las fórmulas propias de una comisión o de un mandato, sino más bien con el ejercicio de una función estatal sostenida por el Parlamento pero no instrumentalizada por el mismo".

Así las cosas, ¿qué tipo de órgano es, entonces, el Defensor del Pueblo y qué clase de relaciones establece con las Cortes Generales? Existe un amplio consenso doctrinal — que, por supuesto, compartimos- en torno a la idea de que el Defensor del Pueblo no es, en modo alguno, un órgano interno de las Cámaras, en el bien entendido de que las competencias que la Constitución reserva al Defensor del Pueblo éste las ostenta a título propio y no como órgano al servicio del Parlamento. Es decir, el Defensor del Pueblo no es un órgano instrumental, integrado en la estructura orgánica de las Cortes Generales, a través del cual aquéllas llevan a cabo funciones que pertenecen al ámbito de su competencia sino un órgano con entidad constitucional propia ${ }^{16}$.

Próximo al anterior, pero mucho más intenso es el debate acerca de si el Defensor del Pueblo - del que ya sabemos que no es un estricto comisionado del Parlamento- tiene la naturaleza de órgano auxiliar de éste o, por el contrario y según acabamos de decir, ostenta, por sí mismo, la consideración de órgano de relevancia constitucional. Es muy cierto que, al menos en apariencia, esta institución comparte elementos de una y otra categoría jurídica, por lo que, según el criterio diferenciador sobre el que se ha hecho hincapié, la doctrina ha llegado a conclusiones muy diferentes ${ }^{17}$.

En nuestra opinión, la función que la Constitución le encomienda al Defensor del Pueblo no se limita, ni mucho menos, a las típicas labores técnicas de vigilancia, control, asesoramiento o consulta a realizar por el órgano auxiliar en favor de un órgano principal a quien se presta auxilio. El Defensor del Pueblo decide —y lo hace, además, libremente y según su criterio— sobre la admisión de quejas, su tramitación y resolución; sobre las sugerencias y recomendaciones que realiza a los diferentes órganos de la Administración Pú-

15 SAINZ MORENO, F., "Defensor del Pueblo y Parlamento. Relaciones con las Cámaras", en AA.VV., Diez Años de la Ley Orgánica del Defensor del Pueblo. Problemas y Perspectivas, Universidad Carlos III, Madrid, 1992, págs. 41 y 42.

16 Vid., por todos, PÉREZ-UGENA COROMINA, M.: «[El Defensor del Pueblo] no puede considerarse un órgano interno de las Cámaras, ya que es dudoso que las competencias de que éste sea titular puedan ser consideradas como competencias de las Cortes, no es, por tanto, posible imputar sus decisiones a éstas sino a él mismo por actuar en nombre propio y según su criterio", en Defensor del Pueblo y Cortes Generales... op. cit., pág. 33.

17 Vid. una postura muy distinta a la que aquí se va a defender en AGUILAR FERNÁNDEZHONTORIA, J. "A propósito del Defensor del Pueblo: rasgos definidores de la posición jurídica de los órganos auxiliares", en AA.VV., Cortes Generales, Vol. I, IEF, Madrid, 1987. 
blica; y, fundamentalmente, sobre si ejercitar o no, y en qué concretos términos, su legitimación para interponer recursos de inconstitucionalidad y de amparo ante el Tribunal Constituciona ${ }^{18}$. Muy lejos, por tanto, de lo que sería una prestación de servicios de colaboración administrativa de orden técnico, propia de los órganos auxiliares ${ }^{19}$.

Entendemos, en consecuencia, que si bien el Defensor del Pueblo no se configura en nuestro ordenamiento como un órgano constitucional en el más estricto sentido del término ${ }^{20}$, entendiendo por tales aquéllos que hacen de manera insustituible al modelo de relación entre poderes -órganos constitucionales esenciales o indefectibles-, sí existe como órgano constitucionalizado -órgano constitucional no esencial o defectible-; lo que, si no redunda en la dialéctica institucional básica del sistema, sí afecta, y mucho, a la existencia, definición y garantía de tales órganos ${ }^{21}$. Dicho de otra manera, se trata de un órgano encuadrable dentro de esas "instituciones garantizadas" por la Constitución a las que ya muy tempranamente se refirió el Tribunal Constitucional describiéndolas como "elementos arquitecturales indispensables del orden constitucional y las normaciones organizativas, pero a diferencia de lo que sucede con las instituciones supremas del Estado, cuya regulación orgánica se hace en el propio Texto Constitucional, en éstos la configuración institucional concreta se defiere al legislador ordinario al que no se fija más límite que el del reducto indispensable o núcleo esencial que la Constitución garantiza, ${ }^{22}$. Estaríamos, pues, ante un órgano constitucionalizado ${ }^{23}$, al menos

18 Vid., en el mismo sentido, SAINZ MORENO, F., "Defensor del Pueblo y Parlamento...", op. cit., págs. 45 y 46.

19 Algunos autores que aceptan la tesis del Defensor del Pueblo como órgano auxiliar de las Cortes Generales, defienden también, pese a ello, la plena autonomía orgánica y funcional de esta institución. Vid. VARELA SUANZES-CARPEGNA, J.: «[...] la relación de auxiliariedad excluye tanto una relación de paridad, que es la que liga a los órganos constitucionales entre sí, como una relación de jerarquía o subordinación, que es la que vincula a un órgano interno con el órgano principal en el cual se inserta. [...] el Defensor del Pueblo goza frente a las Cortes de una indudable autonomía, tanto en el plano orgánico como en el funcional", en "La naturaleza jurídica del Defensor del Pueblo", op. cit., págs. 64 y 65.

20 Sobre el concepto de órgano constitucional, vid., v.g., GÓMEZ MONTORO, A.J., El conflicto entre órganos constitucionales, CEPC, Madrid, 1992; y DÍEZ-PICAZO, L.M.: Voz "Órganos constitucionales", en AA.VV., Enciclopedia Jurídica Básica, Civitas, Madrid, 1995, Vol. III, págs. 4695 y ss.

21 Por lo que se refiere a la paralela situación de los comisionados autonómicos, vid. la distinción de GARRORENA MORALES entre órganos estatutarios inmediatos o esenciales y órganos estatutarios mediatos o no esenciales en "Comentario al artículo 20", en GARCÍA CANALES, M. y GARRORENA MORALES, A. (Coords.), Comentarios al Estatuto de Autonomía de la Región de Murcia, Co-edición Gobierno Regional, Consejo Jurídico, Asamblea Regional y CajaMurcia, Murcia, 2005, págs. 916-919.

22 STC 32/1981, de 28 de julio. La cursiva es mía.

23 Seguimos aquí el concepto utilizado por MERINO MERCHÁN, F.: “Constitucionalizados [en el sentido de] colocados en una posición preeminente por ejercer funciones de garantía, control y consulta, con plena autonomía orgánica y funcional, y cuya finalidad institucional es velar por la observancia de la Constitución y del resto del ordenamiento. En el vigente Derecho Público español bajo estas rúbricas se conocen sólo tres órganos: el Defensor del Pueblo, el Tribunal de 
en sus elementos esencialísimos, con todas las consecuencias que, en nuestro sistema jurídico-constitucional, de ello se derivan. Y, sin lugar a dudas, la autonomía orgánica y funcional del Defensor del Pueblo, corolario inexcusable de la misión que la Constitución le encomienda, forma parte de ese «reducto indispensable" constitucionalmente garantizado.

¿Y cuál es el concreto alcance de tal afirmación respecto de la cuestión que nos ocupa? En nuestro criterio, la potestad de autorreglamentarse es, no ya un elemento principal, sino la piedra angular donde se sostiene esa autonomía orgánica y funcional. Sin la capacidad para normar la estructura y el trabajo interno de la institución tal autonomía, sencillamente, no existiría ${ }^{24}$. Por esta razón, debemos censurar que algunos de los autores más autorizados en esta materia, tras defender sin ambages la autonomía orgánica y funcional del Defensor del Pueblo garantizada por la propia Constitución no critiquen la injustificable limitación de la misma que las Cortes operan al interferir en la aprobación del Reglamento de Organización y Funcionamiento de esta institución. Así, Pérez Calvo afirma que "los preceptos constitucionales referidos al Defensor del Pueblo ofrecen criterios más que suficientes para inclinarse por esta alternativa [plena autonomía de la institución]. Sin pretender ser exhaustivos, podemos señalar aquí cómo por mandato constitucional las Cortes se ven abocadas a regular y designar un alto comisionado suyo cuya función es la defensa de los derechos y libertades proclamados por la Constitución, [...] legitimado para impugnar, en aras de la defensa de los derechos que se le encomienda, los actos de las Cortes", para añadir a continuación que tal circunstancia "aconseja la configuración de un Defensor del Pueblo autónomo" 25 . Verdaderamente, ¿tan sólo lo aconseja? ¿Podría, acaso, haber hecho algo distinto el legislador orgánico? Entendemos que no. La autonomía del Defensor del Pueblo y, en particular, su capacidad de autorreglamentación, está garantizada por la Constitución - y por los Estatutos de Autonomía respecto de sus homólogos autonómicos-. Por tanto, lo que hace el artículo 6 LODP - y los simétricos preceptos de las correspondientes leyes autonómicas- no es sino recoger el mandato constitucional de configurar una institución orgánica y funcionalmente autónoma que pueda ejercer con plena libertad la importante función que la Norma Fundamental le encomienda. Una declaración la de esos preceptos que resulta — claro está— inclusiva del poder de autonorma-

Cuentas y el Consejo de Estado", en Instituciones de Derecho Constitucional, Centro de Estudios Superiores Ramón Carande-Beramar, Madrid, 1994, pág. 708.

24 Entendemos trasladables aquí la reflexión que, respecto de la potestad de autoformación del Tribunal Constitucional, hace GARRORENA MORALES, A.: «[...] la capacidad de autonormación del Tribunal es consecuencia de ese principio general según el cual pertenece a la propia condición de autonomía de ciertos órganos constitucionales del Estado (el Parlamento desde siempre; pero no sólo él) la atribución de determinadas potestades de autoorganización, constituidas así en auténticas garantías de su independencia funcional", en "Comentario al artículo 165. La reserva del Tribunal Constitucional a Ley Orgánica", en ALZAGA VILLAAMIL, O. (Dtor.), Comentarios a la Constitución Española de 1978, Edersa, Madrid, 1999, pág. 402.

25 PÉREZ CALVO, A.: “Rasgos esenciales del Defensor del Pueblo...”, op. cit., pág. 68. 
ción de estos órganos. Así pues, lo previsto por la ya citada Ley reguladora del Ararteko vasco —-El Reglamento interno del Ararteko será aprobado por él mismo» - y por el también referido Estatuto de Autonomía catalán — «El Sindic de Greuges goza de autonomía reglamentaria»-, lejos de constituir sendas excepciones a una regla general que limita la capacidad autonormadora del Defensor del Pueblo y los comisionados autonómicos, son, por el contrario, una correctísima concreción expresa del mandato estatutario, la primera; y una explícita estipulación estatutaria de lo que se encuentra implícito en la Constitución y en el resto de Estatutos de Autonomía, la segunda.

De este modo, quedaría, ahora sí, suficientemente justificada la improcedencia de la participación — cualquiera que sea el órgano interno a través del cual se vehicule y el alcance de la misma- de las Cortes Generales y de los Parlamentos territoriales en la elaboración, aprobación y reforma de la norma en la que se concreta el poder autonormador del Defensor del Pueblo y de los comisionados autonómicos: su Reglamento de Organización y Funcionamiento interno.

\section{LA EXCLUSIÓN DEL RÉGIMEN INTERNO DEL DEFENSOR DEL PUEBLO DE LA RESERVA A PARLAMENTO.}

Entrando a plantear el problema desde la perspectiva de la teoría de las fuentes del Derecho, va de suyo que si afirmamos que, por las razones descritas, no procede intervención parlamentaria alguna en la aprobación y reforma del Reglamento de Organización y Funcionamiento del Defensor del Pueblo, eso significa que entendemos que, por supuesto, el régimen interno de esta institución no forma parte del ámbito material propio de ninguna norma aprobada por el Parlamento, singularmente, de los Reglamentos de las Cámaras y del Estatuto del Personal al servicio de las Cortes (art. 72 CE). No obstante, la existencia de algunos pronunciamientos doctrinales que defienden la tesis contraria nos obliga a insistir algo más en este concreto punto.

En efecto, en coherencia con lo visto al abordar el problema de la titularidad de esta capacidad normadora, el sector encabezado por Oehling Ruiz al que ya nos referimos entiende no sólo que corresponde al Parlamento la aprobación final de la norma reguladora del régimen interno del Defensor del Pueblo, sino que ésta además ni siquiera constituye por sí misma un tipo normativo distinto y específico. Antes al contrario, tal regulación habría de integrarse en los Reglamentos de las Cámaras - y en el de las Cortes Generales, llegado el caso-, excluyendo así, por tanto, incluso la iniciativa del Defensor del Pueblo en la elaboración del texto. Con este punto de partida, y a la vista del concreto contenido del Reglamento de Organización y Funcionamiento de la institución, el referido autor alcanza una serie de conclusiones que entendemos especialmente censurables:

Por un lado, critica que este Reglamento no se haya ocupado, entre otras muchas cuestiones, de regular, por ejemplo, la tramitación en Cortes de 
los informes que el Defensor del Pueblo presenta ante las mismas o los procedimientos para informar y dirigirse, en su caso, a las Diputaciones Permanentes $^{26}$. Asimismo, de otro lado, afirma que habrá que estimar derogadas por el Estatuto del Personal de las Cortes Generales, que es norma posterior en el tiempo, las previsiones del Reglamento de Organización y Funcionamiento relativas al personal administrativo puesto al servicio del Defensor del Pueblo; todo ello, entendemos, en la inteligencia de que se trata de dos tipos normativos del mismo rango y naturaleza ${ }^{27}$.

Se hace, por tanto, preciso insistir en la identificación del Reglamento de régimen interno del Defensor del Pueblo como un tipo normativo diferenciable de estas dos normas de origen parlamentario que son los Reglamentos de las Cámaras y el Estatuto del Personal al servicio de las Cortes Generales. Como venimos defendiendo, este Reglamento no es más —ni menos- que la norma reguladora de la organización y el funcionamiento interno de la institución que el Defensor del Pueblo debería poder darse a sí mismo, en virtud de su potestad de autorreglamentación constitucionalmente garantizada. Es, pues, norma sin rango, fuerza ni valor de ley, con efectos exclusivamente ad intra del órgano y con un ámbito material limitado - en los concretos términos que más tarde veremos- a los aspectos estrictamente orgánicos y funcionales del Defensor del Pueblo.

Por su parte, los Reglamentos de las Cámaras y el Estatuto del Personal de las Cortes tienen una naturaleza claramente distinta, tanto desde el punto de vista formal como material. Desde una perspectiva formal, ambas son, según consolidada jurisprudencia constitucional, normas incardinadas directamente en la Constitución, sin ley interpuesta, principal razón que las diferencia claramente de los reglamentos administrativos o de régimen interno ${ }^{28}$ :

26 OEHLING RUIZ, H.: "El Reglamento no ha desarrollado partes importantes de la LODP, como son las referentes a las actuaciones de oficio y a las quejas, en numerosos aspectos necesitados de alguna regulación. Ni en aspectos propiamente parlamentarios, como son los relativos al trámite de sus informes en las Cámaras, hoy regulado provisionalmente por resoluciones presidenciales, ni la forma de dirigirse e informar en su caso a las Diputaciones Permanentes", en "El Defensor del Pueblo: algunos problemas...", op. cit., pág. 105.

27 OEHLING RUIZ, H.: "Utiliza [el ROFDP] un régimen disciplinario más duro que el establecido para el personal de las Cortes, que, por cierto, habrá que entender derogado por el más reciente Estatuto del Personal de las Cortes, el cual aunque no menciona para nada al personal al servicio del Defensor del Pueblo, es norma posterior al Reglamento del Defensor del Pueblo", en "El Defensor del Pueblo: algunos problemas...", op. cit., pág. 105.

28 En este mismo sentido, vid., por todos, GARCÍA-ESCUDERO MÁRQUEZ, P.: "Los Reglamentos de las Cámaras son normas incardinadas en la Constitución (sin ley interpuesta, con rango de ley (por su inclusión en la relación de normas del artículo 27 LOTC que pueden ser objeto de control de constitucionalidad pero desprovista de la fuerza [activa] propia de la Ley (STC 119/1990). Con ello se hace alusión al ámbito de eficacia de los reglamentos, restringidos a la ordenación interna de la vida de las Cámaras (STC 44/1995), de modo que sus efectos ad extra están limitados a otros órganos en su relación con aquéllas como consecuencia del ejercicio de sus funciones constitucionales. No obstante, ello no quiere decir que se trate de un mero reglamento interno, sino que su naturaleza es de mayor relevancia y alcance (STC 179/1989) y de ahí que pueda ser objeto de recurso de inconstitucionalidad", en "Comentario al artículo 72.1", en ALZA- 
"No se trata, en efecto, de una disposición de categoría inferior a la ley, sino, antes bien, de una norma que, de acuerdo con la reserva constitucional establecida, goza de fuerza de ley y que, asimismo, por proceder del Poder Legislativo posee valor de ley [...]. No es equiparable en manera alguna a las normas reglamentarias, ya que, a diferencia de éstas, aquél no se halla subordinado a la ley, sino directamente incardinado y vinculado a la Constitución. [...] De lo que se infiere, como conclusión que sus normas son primarias, sólo justiciables ante el Tribunal Constitucional, ${ }^{29}$.

Además, desde un punto de vista material, son normas cuyo ámbito está claramente delimitado: ostentan el monopolio sobre las materias que la Constitución les encomienda - vertiente positiva - y no pueden ocuparse de ninguna otra - vertiente negativa- ${ }^{30}$. ¿Y cuál es, en concreto el ámbito material al que deben circunscribirse cada una de ellas? Por un lado, el Estatuto del Personal de las Cortes se ha de referir exclusivamente a la "determinación de las diversas clases de personal, la regulación del acceso al empleo parlamentario y las condiciones de permanencia en el mismo, el establecimiento de los derechos y deberes de dicho personal, de las situaciones administrativas en que éste puede encontrarse y su régimen disciplinario "31. Por su parte, los Reglamentos de las Cámaras han de limitarse a desarrollar las cuestiones que la Constitución - el Estatuto de Autonomía, en el caso de los Parlamentos autonómicos ${ }^{32}$ - les reserva expresamente (v.g. arts. 72.1, 79.1 y 2, 80, 87.1, 89.1, entre otros) y también todas aquellas otras que la Constitución establezca como funciones propias de las Cortes Generales aunque no haga una referencia expresa a su necesario desarrollo vía Reglamento parlamentario y, dentro de ellas, particularmente, todos aquellos aspectos procesales y estructurales que conforman el núcleo duro de la autonomía parlamentaria ${ }^{33}$. Que-

GA VILlAAMIL, O. (Dtor.), Comentarios a la Constitución Española de 1978, Edersa, Madrid, 1999, págs. 406-407.

29 STC 139/1988, de 8 de julio.

30 Vid., por todos, DE OTTO, I., Derecho Constitucional. Sistema de Fuentes, Ariel Derecho, Barcelona, 1989, pág. 225

31 MATía PORTILLA, E.: «El Estatuto del Personal de las Cortes Generales como fuente de Derecho", en Corts. Anuario de Derecho Parlamentario, n. ㅇ 22, págs. 182 y 183.

32 En palabras de BASSOLS COMA, "en el ámbito estrictamente interno del ordenamiento jurídico autonómico, el reglamento ha de llevar a cabo, hacia el Estatuto, una función similar a la que realicen los reglamentos parlamentarios estatales hacia la Constitución. Dicho en otras palabras, el reglamento ha de ejecutar las previsiones estatutarias en el ámbito material que le es propio, con lo cual el principio de relación entre ley y reglamento parlamentario en el ámbito del ordenamiento autonómico continúa invariable", en "Organización institucional y régimen jurídico de las Comunidades Autónomas", en AA.VV., La Organización Territorial del Estado, Vol. I, IEF, Madrid, 1984, pág. 190.

33 Todo ello sin excluir que esta delimitación constitucional no sólo opera en sentido positivo, sino también, excepcionalmente, en sentido negativo, obligándonos a admitir que existen materias propias del Derecho Parlamentario sustraídas expresamente por la Constitución del ámbito de los Reglamentos de las Cortes. Cuestiones que el constituyente estimó conveniente dejar fuera de la autonomía de cada una de las Cámaras y cuyo tratamiento unitario prefirió reservar a la ley (normalmente, orgánica). Vid., v.g., la iniciativa legislativa popular prevista en el artículo 87.3 CE. 
daría, por tanto, en virtud del criterio aquí defendido, claramente fuera de estas reservas a Parlamento la regulación del régimen interno del Defensor del Pueblo, que ostenta sus competencias - ya lo sabemos- a título propio y no por comisión, delegación o mandato parlamentario.

¿Quiere ello decir que ni los Reglamentos de las Cámaras ni el Estatuto del Personal de las Cortes pueden regular ninguna cuestión relacionada con la institución del Defensor del Pueblo? Por supuesto que no. Toda aquella actividad propiamente parlamentaria relativa a las relaciones de las Cortes Generales con el Defensor del Pueblo - v.g. la tramitación en sede parlamentaria de los informes anuales, la composición y funcionamiento de la Comisión Mixta Congreso-Senado de relaciones con el Defensor del Pueblo, etc.- - ha de ser normada por el Reglamento de la Cámara que corresponda, tal y como ha venido sucediendo hasta la fecha ${ }^{34}$. Asimismo, el Estatuto del Personal de las Cortes, si bien no regula ninguna cuestión directamente relacionada con el Defensor del Pueblo, podrá resultar de aplicación al personal adscrito a este órgano, como veremos a continuación, por remisión expresa del propio Reglamento de Organización y Funcionamiento interno de la institución.

\section{LAS RELACIONES DEL REGLAMENTO INTERNO CON LA LEY ORGÁNICA DEL DEFENSOR DEL PUEBLO: CONFLICTO FRONTERIZO}

Así deslindado el ámbito propio del Reglamento de Organización y Funcionamiento del Defensor del Pueblo respecto de los Reglamentos de las Cámaras y del Estatuto del Personal de las Cortes no parece que puedan generarse - salvo manifiesta impericia del legislador- claras zonas de fricción entre estos tipos normativos. En cambio, las líneas rojas que separan a dicho Reglamento de la LODP —o de las normas autonómicas correspondientes, en el caso de los comisionados regionales- son mucho más difíciles de trazar, y es allí, por tanto, donde más frecuentemente podremos encontrar determinados solapamientos normativos.

Si bien venimos defendiendo que la autonomía orgánica y funcional del Defensor del Pueblo y, con ella, su potestad de autorreglamentación tienen amparo y garantía en el artículo 54 de la Constitución, no es menos cierto que también en ese mismo precepto encontramos una reserva expresa al legislador orgánico para que establezca el régimen jurídico de la institución, en unos

34 Vid., Resolución de la Presidencia del Congreso de los Diputados sobre la tramitación ante el Pleno de los informes anuales o extraordinarios del Defensor del Pueblo, de 21 de abril de 1992; Resolución de la Presidencia del Senado sobre la tramitación en el Pleno de la Cámara de los informes del Defensor del Pueblo, de 28 de abril de 1992; y Resolución de las Mesas del Congreso y del Senado sobre la organización y el funcionamiento de la Comisión Mixta de relaciones con el Defensor del Pueblo, de 21 de abril de 1992. 
términos, además, absolutamente amplios: «Una ley orgánica regulará la institución del Defensor del Pueblo [...]”. Del mismo modo, la mayor parte de las Comunidades Autónomas han reproducido en sus Estatutos de Autonomía este tipo de formulación ${ }^{35}$, optando algunas otras por concretar algo más el contenido de tal reserva, haciendo referencia expresa a que la ley autonómica debe regular, entre otras cuestiones, la "organización y funcionamiento de la institución "36, en aparente alusión al ámbito propio del Reglamento.

Esta circunstancia, la expresa reserva constitucional $-\mathrm{O}$ estatutaria- hecha en tales términos al legislador orgánico —o autonómico-, unida a la evidencia de que la norma legal ha de anteceder al reglamento - por la obvia y sencilla razón de que sin ley no existe institución alguna que, en uso de su autonomía, pueda autorreglamentarse-, podría llevarnos a pensar, en una primera lectura del artículo 54 de la Constitución, que se establece una relación de subordinación o jerarquía entre la Ley Orgánica y el Reglamento de Organización y Funcionamiento interno. No creemos, sin embargo, que ésta sea una conclusión válida.

Ambos tipos normativos gozan de una habilitación constitucional que viene referida a sujetos distintos, que persiguen finalidades diferentes y relativas a ámbitos materiales igualmente dispares. La reserva que se hace al Parlamento y, en concreto, al legislador orgánico en el caso del Defensor del Pueblo estatal, tiene como principal objetivo excluir al legislador no cualificado y, por supuesto, al Ejecutivo de la regulación de la más relevante garantía institucional que los derechos y libertades fundamentales tienen en nuestro sistema. Por su parte, el reconocimiento de la potestad del Defensor del Pueblo para establecer su propio régimen de organización y funcionamiento interno busca garantizar el libre y eficaz ejercicio de las funciones de esta institución frente a posibles injerencias de otros órganos, muy en particular, frente a las Cortes Generales. Lógicamente, del concreto uso que haga el legislador orgánico de su reserva dependerán en buena medida las condiciones de ejercicio de la autonomía reglamentaria del Defensor del Pueblo — v.g., la organización interna del trabajo de la institución será distinta dependiendo de qué concretos medios para supervisar la actividad de la Administración ponga a su disposición la LODP—; pero ello no impide, en modo alguno, que cada tipo

35 Vid., v.g., art. 22 EALR: "Sin perjuicio de la institución del Defensor del Pueblo prevista en el artículo 54 de la Constitución y en coordinación con la misma, la Comunidad Autónoma de La Rioja podrá crear mediante ley una institución similar que actuará como comisionado del Parlamento de La Rioja y que, designado por éste, se ocupará de la defensa de los derechos y libertades comprendidos en el Título I de la Constitución, a cuyo efecto podrá supervisar la actividad de la Administración autonómica, dando cuenta de ello al Parlamento".

36 Vid., v.g., art. 18 EAC-L: "1. El Procurador del Común es el Alto Comisionado de las Cortes de Castilla y León, designado por éstas, que actúa con independencia para la protección y defensa de los derechos constitucionales de los ciudadanos y los derechos y principios reconocidos en el presente Estatuto frente a la Administración de la Comunidad, la de sus entes locales y la de los diferentes organismos que de éstas dependen. 2. Una ley de las Cortes de Castilla y León regulará las competencias, organización y funcionamiento de esta institución". 
de fuente conserve un concreto ámbito material, aunque éste no siempre resulte de fácil delimitación. No hay, por tanto, relación de jerarquía entre ambas normas. En palabras de Garrorena Morales, referidas a la relación LOTCReglamento de organización y Personal del TC, que entendemos trasladables aquíi ${ }^{37}$ :

«[...] uno de esos ámbitos es de determinación anterior al otro, cosa que es muy distinta a que lo sea de determinación superior. Ésa es la razón por la cual el primero puede variarle al segundo las condiciones de su ejercicio, pero no puede, en cambio, negarle o vaciarle su contenido más sustantivo".

Existiría, pues, un contenido esencial del Reglamento que la ley no puede agotar. Ámbito que habría de quedar restringido, exclusivamente, a las condiciones relativas al Gobierno interior del órgano, la organización del trabajo y el régimen de sus distintos servicios; esto es, todo aquello que únicamente tiene incidencia sobre la organización y el funcionamiento interno del órgano, sin ningún tipo de eficacia ad extra de la institución. Estaríamos, por tanto, ante lo que Balaguer Callejón denominó Derecho o potestad estatutaria $^{38}$ :

“La potestad estatutaria puede estar fuertemente sometida a la ley [...]. Sin embargo, su sola condición de Derecho estatutario implica ya, por sí misma, la obligación de la ley [...] de respetar las atribuciones competenciales que conlleva, hasta tanto no sean levantadas de forma expresa. [El Derecho estatutario] está integrado por todas aquellas normas que (se denominen o no estatutos) tienen como función primordial la determinación de las reglas básicas de organización de los diversos órganos y entes".

Así las cosas, entendemos perfectamente ajustado a Derecho, pese a las críticas de algún sector de la doctrina ${ }^{39}$, que sea la LODP la norma que regule el régimen de incompatibilidades del Defensor del Pueblo, extremo que nada tiene que ver con su funcionamiento interno y sí mucho con las condiciones de designación de su titular y con las relaciones de éste ad extra de la institución. Por el contrario, en nuestra opinión, se excede del ámbito de su competencia el legislador — en este caso, el legislador catalán- cuando regula el régimen jurídico de estructuras administrativas del Sindic de Greuges como, por ejemplo, la del equipo de trabajo para la prevención de la tortura

37 GARRORENA MORALES, A.: “Comentario al artículo 165...”, op. cit., pág. 408.

38 BAlaguer CAllejón, F., Fuentes del Derecho... op. cit., pág. 99.

39 PÉREZ-UGENA COROMINA, M: “...] respecto de algunas cuestiones contempladas [en la LODP] hubiera resultado más apropiado su posterior inclusión en el Reglamento [...] ya que [...] forman parte de la misma aspectos típicamente reglamentarios. Así ocurre, por ejemplo, con la exhaustiva regulación de que es objeto el tema de las incompatibilidades a que puede quedar afecto el Defensor del Pueblo", en Defensor del Pueblo y Cortes Generales, op. cit., pág. 55. 
y de otros tratos o penas crueles, inhumanos o degradantes; o cuando realiza una detalladísima regulación de la tramitación interna de los distintos procedimientos de investigación de los que se sirve el Sindic ${ }^{40}$.

Además, es importante destacar que la delimitación del ámbito material del Reglamento de Organización y Funcionamiento del Defensor del Pueblo frente a su ley reguladora también opera en sentido negativo, esto es, el reglamento no puede ocuparse de aquellas cuestiones que el legislador no atiende pese a pertenecer a su ámbito, puesto que la condición de esta norma reglamentaria no es, ni mucho menos, la propia de los reglamentos administrativos $^{41}$. De este modo, el Reglamento de régimen interno del Defensor del Pueblo no podría, por ejemplo, ampliar el ámbito de competencias de la institución, confundiendo de esa manera las dimensiones interna y externa de lo que se ha de entender por "organización y funcionamiento" del órgano. Los Defensores del Pueblo no pueden ostentar más competencias que aquellas que el legislador pone a su disposición para el mejor cumplimiento de la función que tienen constitucional o estatutariamente asignada. Por esta razón, entendemos especialmente censurable el establecimiento en algunos Reglamentos de Defensores del Pueblo autonómicos de cláusulas residuales como la del artículo 7.s) ROFDP de la Región de Murcia ${ }^{42}$, en virtud de la cual, «además de las competencias básicas establecidas por la ley" corresponderá a este comisionado autonómico "cualesquiera otras que no vengan expresamente atribuidas a otro órgano".

Finalmente, hemos de referirnos a un concreto aspecto del régimen jurídico del Defensor del Pueblo que ilustra muy bien cómo la línea fronteriza que separa la ley y el reglamento de la institución no siempre resulta fácil de trazar: el régimen del personal al servicio del Defensor del Pueblo.

Como prueba el hecho de que tanto la LOTC como la LOPJ hayan incluido expresamente esta materia en el ámbito de autonomía de los órganos

40 Vid. arts. 76 y $42-48$ de la Ley 24/2009, de 23 de diciembre, del Sindic de Grenges. Resulta especialmente sorprendente y censurable que la única Comunidad Autónoma que ha hecho un reconocimiento expreso en su Estatuto de la «autonomía reglamentaria, organizativa, funcional y presupuestaria" de su comisionado autonómico haya aprobado la que, sin duda, es, con muchísima diferencia, la ley autonómica más extensa y reglamentista de todas las referidas a esta materia. Por ello, será particularmente interesante, a nuestros efectos, observar en qué concretos términos se aprueba el Reglamento de Organización y Funcionamiento del Sindic de Greuges, todavía en elaboración.

$41 \mathrm{Vid}$., en el mismo sentido, en referencia a las relaciones de la LOTC con el Reglamento de régimen interno de ese órgano, GARRORENA MORALES, A.: "La potestad de autonormación que el Tribunal Constitucional tiene atribuida es una facultad que no existe para la integración o el desarrollo segundo de la LOTC (ésta sería una nueva forma de confundir la posición y condición de las normas que el Tribunal adopta con la posición y condición de los reglamentos administrativos, modificando ahora tan sólo su origen), sino que existe exclusivamente para garantizar la autonomía del Tribunal en cuanto afecta a su gobierno interior, razón por la cual sólo puede operar en esta zona, lo que, visto en su propio terreno, esto es, en el terreno de la independencia funcional de dicho órgano, no es precisamente poco", en "Comentario al artículo 165 ..., op. cit., pág. 404.

42 Aprobado por la Mesa de la Asamblea Regional de Murcia el 4 de diciembre de 2009. 
constitucionales a los que se refieren ${ }^{43}$, estamos, sin duda, ante una de esas cuestiones que se integran en el contenido propio de la autonomía orgánica y funcional de este tipo de instituciones. ¿Cómo lo ha abordado nuestro legislador respecto de los Defensores del Pueblo? La LODP y algunas leyes autonómicas han optado por dejar abierta la puerta para que sea el reglamento la norma que regule el régimen del personal a su servicio. Se han limitado a establecer que "las personas que se encuentren al servicio del Defensor del Pueblo, y mientras permanezcan en el mismo, se considerarán como personal al servicio de las Cortes" (art. 35.1 LODP) ${ }^{44}$. A este respecto, la doctrina ha entendido que tal consideración "se refiere a que el personal del Defensor del Pueblo no tiene la condición de funcionario de la Administración", pues precisamente se busca "un indudable distanciamiento de ésta a efectos de ser imparcial" al ejercer la función de supervisar su actividad. No se trata, por tanto, ni de una regulación mínimamente suficiente y propia de la cuestión ni de una remisión de la ley al Estatuto del Personal de las Cortes ${ }^{45}$ :

"No puede considerarse que [el art. 35.1 LODP] defina un régimen jurídico en sentido propio; no establece cuál es el sistema de acceso del personal no asesor, ni sus derechos ni sus deberes; y ni siquiera existe una remisión directa a un Estatuto de Personal que le sirva de referencia, el de las Cortes Generales, por ejemplo, si es que se quiere dar carácter sustantivo al hecho de ser personal al servicio de las Cortes [...].

De este modo, es el Reglamento de Organización y Funcionamiento del Defensor del Pueblo la norma que define el régimen jurídico del personal al servicio de la institución, de la que depende orgánica y funcionalmente: «El personal al servicio del Defensor del Pueblo tendrá la consideración de personal al servicio de las Cortes, sin perjuicio — reza el art. 27.1 del Reglamento- de la dependencia orgánica y funcional del Defensor del Pueblo".

Por el contrario, en las leyes reguladoras de esta institución de algunas Comunidades Autónomas encontramos alusiones expresas al correspondiente Estatuto del Personal del Parlamento autonómico como norma aplicable al personal al servicio del Defensor del Pueblo de este territorio, lo que ha maniatado - de modo incorrecto, según nuestro criterio- al Reglamento de tales comisionados autonómicos, que no han dispuesto regulación alguna respecto de su propio personal. Valga, por todos ${ }^{46}$, el ejemplo murciano:

43 Art. 2.2 LOTC: "El Tribunal Constitucional podrá dictar reglamentos sobre su propio funcionamiento y organización, así como sobre el régimen de su personal y servicios [...]. Art. 110.1 LOPJ: «El Consejo General del Poder Judicial podrá dictar reglamentos sobre su personal, organización y funcionamiento en el marco de la legislación sobre la función pública".

44 Vid. también, v.g., art. 34.1 Ley 9/1983, de 1 de diciembre, del Defensor del Pueblo Andaluz.

45 ALONSO SECO, J.M.: "Comentario al artículo 35.1", en ROVIRA VIÑAS, A. (Dtor.), Comentarios a la LODP, Thomson-Aranzadi, Navarra, 2002, págs. 877 y 880.

46 Vid. también, v.g., art. 41 Ley 7/2001, de 31 de julio, del Diputado del Común de Canarias. 
Art. 52.3 Ley 6/2008, de 20 de noviembre, del Defensor del Pueblo de la Región de Murcia: «El personal asesor y administrativo que se encuentre al servicio del Defensor del Pueblo de la Región de Murcia, mientras permanezca en el mismo, tendrá la consideración de personal de la Asamblea Regional de Murcia, correspondiéndole a aquél su asignación de destino, y siéndole aplicable al mismo igual régimen jurídico que al personal de la Cámara".

Pero, en el ámbito autonómico, no sólo encontramos invasiones de la ley en el ámbito de los Reglamentos de Organización y Funcionamiento de estas instituciones, sino también estipulaciones reglamentarias que exceden, con mucho, los límites de lo que constituye su ámbito propio de actuación. Es el caso, por ejemplo, de aquellos reglamentos que prevén, además del régimen orgánico y funcional de su personal, un régimen disciplinario específico y distinto del previsto en el Estatuto del Personal del Parlamento correspondiente. En estos supuestos, en los que el Defensor del Pueblo, además de ejercer la potestad sancionadora - lo hace en todos los casos-, también tipifica y gradúa en su Reglamento los diferentes tipos de faltas y sus correlativas sanciones, así como un completo procedimiento sancionador ${ }^{47}$, se incurre en una clara vulneración del principio de legalidad predicable respecto de todo régimen disciplinario. Es consolidada jurisprudencia constitucional que resulta contrario a lo previsto por el artículo 25.1 CE y concordantes la regulación reglamentaria de infracciones y sanciones carente de asidero legal e, incluso, la remisión de la misma al reglamento por norma con rango de ley vacía de todo contenido material para la tipificación de ilícitos administrativos y sus correspondientes sanciones ${ }^{48}$. De este modo, en nuestro caso procedería bien que el legislador estableciera un régimen sancionador específico para el personal al servicio del Defensor del Pueblo, bien que se aplicara por remisión el previsto en el Estatuto del Personal al servicio del Parlamento - como sucede en el caso de Galicia ${ }^{49}$ - , para cumplir así con las exigencias constitucionales al respecto.

Así pues, la garantía constitucional —o estatutaria- de la autonomía reglamentaria de los Defensores del Pueblo protege a este tipo normativo frente a posibles injerencias del legislador en el ámbito que le es propio, pero ello no justifica, en modo alguno, que pueda abandonarlo para adentrarse en terrenos reservados a normas con rango de ley. Excesos normativos que, por

47 Vid., v.g., arts. 29-33 del Reglamento de Organización y Funcionamiento del Síndico de Agravios de la Comunidad Autónoma de Valencia, aprobado por la Comisión de Peticiones de las Cortes Valencianas el 21 de septiembre de 1993.

$48 \mathrm{Vid}$., por todas, SSTC 77/1983, de 3 de octubre y 42/1987, de 7 de abril.

49 Art. 26 ROF del Valedor do Pobo Gallego, aprobado por la Mesa del Parlamento de Galicia el 20 de junio de 1997: «El personal al servicio del Valedor do Pobo podrá ser sancionado por la Comisión de faltas disciplinarias de acuerdo con el régimen disciplinario establecido en el Estatuto de Personal del Parlamento de Galicia, en relación con la Ley de Función Pública de Galicia, y conforme al procedimiento previsto en el referido Estatuton. 
supuesto, no encuentran subsanación en el hecho de que el Parlamento, sin encomendarse a nadie — al menos no a nuestro sistema constitucional de fuentes-, haya participado, carente de título alguno para ello, en la aprobación de estos reglamentos a través de las Mesas de las Cámaras.

TITLE: A review of the power to be autonomous of the Ombudsman from the perspective of the sources of law theory.

ABSTRACT: In this paper we defend the constitutional organical and functional autonomy of the Ombudsman that includes the capacity to become autonomous by itself, thus, the Ombudsman holds the capacity to approve and reform unilaterally its Regulation of organization and internal operations without the intervention of the Parliament. From this perspective, we will draw the lines that separate this kind of regulation from others that are border on it: The Regulation of the Parliament, The Parliament Worker's statute and the Organic Law of the Ombudsman.

Resumen: En este trabajo se defiende que el Defensor del Pueblo goza, por imperativo constitucional, de un ámbito de autonomía orgánica y funcional que incluye la potestad para autonormarse internamente, esto es, para aprobar y reformar unilateralmente su Reglamento de Organización y Funcionamiento, sin que resulte procedente intervención alguna de las Cortes Generales en este ámbito. Desde esa premisa, se trazan las líneas rojas que separan a este tipo normativo de otras normas que le son fronterizas: los Reglamentos de las Cámaras, el Estatuto de Personal de las Cortes Generales y la Ley Orgánica del Defensor del Pueblo.

KEY WoRDs: Ombudsman. Internal regulation. Parliament. Power to be autonomous.

Palabras clave: Defensor del Pueblo. Reglamento de Organización y Funcionamiento. Cortes Generales. Potestad de autonormación.

FECHA DE RECEPCIÓN: 28.06.2010. FeCHA DE ACEPTACIÓN: 28.07.2010. 